\title{
SKRINING AKTIVITAS ANTIOKSIDAN FRAKSI EKSTRAK ETANOL KERNEL BIJI LIMUS
}

\author{
${ }^{1}$ Vera Nurviana \\ ${ }^{2}$ Ade Yeni Aprilia \\ ${ }^{3}$ Eka Kartika Nuraini
}

\begin{abstract}
${ }^{1}$ Prodi Farmasi Sekolah Tinggi Ilmu Kesehatan bakti Tunas Husada Tasikmalaya (veranurviana@stikes-bth.ac.id)

${ }^{2}$ Prodi Farmasi Sekolah Tinggi Ilmu Kesehatan bakti Tunas Husada Tasikmalaya (yeni06aprillia@gmail.com)

${ }^{3}$ Prodi Farmasi Sekolah Tinggi Ilmu Kesehatan bakti Tunas Husada Tasikmalaya (ekaaakn@gmail.com)
\end{abstract}

\begin{abstract}
ABSTRAK
Antioksidan merupakan suatu senyawa yang sangat penting dalam memelihara kesehatan. Salah satu bahan alam yang berkhasiat sebagai antioksidan adalah biji limus (Mangifera foetida L.) yang merupakan salah satu spesies mangga dari golongan anacardiaceae yang menyebar di wilayah Indonesia. Penelitian ini bertujuan untuk mengetahui fraksi yang memiliki aktivitas antioksidan yang paling baik pada kernel biji limus dengan metode Bioassay Guided Fractionation melalui reaksi penangkapan radikal bebas DPPH. Penyarian kernel biji buah limus dilakukukan menggunakan metode maserasi dengan pelarut etanol 96\%. Ekstrak selanjutnya difraksinasi dengan pelarut n-heksana, etil asetat, metanol dan air. Aktivitas antioksidan masing-masing fraksi diukur menggunakan spekrofotometer UV-Visible. Hasil menunjukan bahwa fraksi etil asetat ekstrak etanol kernel biji limus memberikan potensi antioksidan yang paling baik yaitu dengan nilai $\mathrm{ES}_{50}$ sebesar $1,164 \pm 0.005 \mu \mathrm{g} / \mathrm{mL}$ (sangat kuat), melebih potensi vitamin $\mathrm{C}$ sebagai pembandingnya.
\end{abstract}

Kata Kunci: Biji limus, Mangifera, Antioksidan, DPPH.

\begin{abstract}
ABSTRAK
Antioxidants are very important compounds in maintaining health. One of the natural ingredients has efficacious as an antioxidant is Limus (Mangifera foetida L.) seeds which is one of the mango species from the Anacardiaceae group which spreads in the territory of Indonesia. This study aims to screen the fraction that has the high antioxidant potential of the Lotus seed kernel used Bioassay-Guided Fractionation method through scavenging reaction of DPPH as free radical. The extraction of the limus seeds was carried out using the maceration method with $96 \%$ ethanol. The extract was then fractionated with $n$-hexane, ethyl acetate, methanol, and water solvents. The antioxidant activity of each fraction was measured
\end{abstract}


using a UV-Visible spectrophotometer. The results showed that the ethyl acetate fraction of the limus seed ethanol extract provided the high antioxidant potential with an ES50 value of 1.164 $\pm 0.005 \mu \mathrm{g} / \mathrm{mL}$ (very strong), exceeding the potential of vitamin $C$ as a standard compound.

Keywords: Limus seeds, Mangifera, Antioxidants, DPPH.

\section{PENDAHULUAN}

Antioksidan merupakan suatu senyawa yang sangat penting dalam memelihara kesehatan. Berbagai bukti ilmiah menunjukkan bahwa senyawa antioksidan mengurangi risiko terhadap penyakit kronis, seperti kanker dan penyakit jantung koroner (Amrun et al., 2007). Produksi antioksidan di dalam tubuh manusia terjadi secara alami untuk mengimbangi produksi radikal bebas. Antioksidan tersebut kemudian berfungsi sebagai sistem pertahanan terhadap radikal bebas, namun peningkatan produksi radikal bebas yang terbentuk akibat faktor stress, radiasi UV, polusi udara dan lingkungan mengakibatkan sistem pertahanan tersebut kurang memadai, sehingga diperlukan tambahan antioksidan dari luar (Muchtadi, 2013).

Antioksidan dari luar tubuh dapat diperoleh dalam bentuk sintesis dan alami (Lie Jinn et al, 2012). Efek samping yang ditimbulkan oleh penggunaan antioksidan sintetik mendorong perkembangan penelitian terhadap antioksidan alami yang lebih aman dan mampu dalam mengurangi radikal bebas dalam tubuh. Antioksidan alami dapat diperoleh dari tumbuhtumbuhan (Ukieyanna, 2012). Antioksidan alami banyak terdapat pada tumbuh-tumbuhan, sayur-sayuran dan buah-buahan (Winarsi, 2007), Salah satu bahan alami yang memiliki aktivitas antioksidan adalah buah mangga. Berdasaran hasil penelitian dilaporkan bahwa sebagian kerabat mangga ternyata memiliki potensi antioksidan kuat yang bermanfaat untuk kesehatan (Mirfat et al, 2016). Mangifera foetida Lour merupakan salah satu spesies buah mangga dari keluarga Anacardiaceae yang menyebar di wilayah Indonesia. Mangifera foetida L., dikenal sebagai mangga bacang,jjjjj pakel atau limus (sunda). Kekerabatan tumbuhan memiliki kemungkinan menghasilkan metabolit sekunder dan efek farmalogis yang serupa.

Penelitian ini bertujuan untuk mengetahui fraksi mana yang memiliki aktivitas antioksidan paling kuat melalui reaksi penangkapan radikal bebas DPPH (2, 2-Difenil-2Pikrihidrazil). Metode DPPH dipilih karena merupakan metode yang sering digunakan untuk mengevaluasi aktivitas antioksidan dari senyawa alami dan ekstrak tanaman. Tingkat perubahan warna menunjukkan potensi penangkal radikal bebas dari senyawa antioksidan, yang disebabkan oleh kemampuannya menyumbangkan hidrogen (Barreira et al, 2008). 


\section{METODE PENELITIAN}

Alat

Alat yang digunakan dalam penelitian ini yaitu maserator, alat gelas kimia, oven (Memmert $\left.{ }^{\circledR}\right)$, waterbath sheaker (Memmert $\left.{ }^{\circledR}\right)$, blender, botol semprot, ball pipet, desikator, mikroskop, lampu sinar UV $254 \mathrm{~nm}$ dan $365 \mathrm{~nm}$, kertas saring Whatman, plat silika gel GF254, corong pisah, mikropipet, kuvet, rotary evaporator vacum (EYELA OSB-2100), chamber, statif, klem bulat, krus porselen, tang krus, loyang, cawan porselen, corong, neraca analitik (Mettler Toledo®), spektrofotometer UV-Vis (Genesys 10S UV-Vis).

\section{Bahan}

Bahan yang digunakan dalam penelitian ini yaitu kernel biji buah limus, etanol 96\%, aquadest, kloroform, asam klorida, toluen, amonia encer, pereaksi Mayer, pereaksi Dragendorff, serbuk Zn, amil alkohol, eter, pereaksi Liebermann-Burchard, pereaksi besi (III) klorida, gelatin $1 \%$, natrium hidroksida, pereaksi vanilin-asam sulfat, silika gel $\mathrm{GF}_{254}$, asam sulfat, n-heksana, etil asetat, DPPH, metanol p.a, asam askorbat (vitamin C) p.a, aseton.

\section{Cara Kerja}

\section{Determinasi Tanaman}

Determinasi kernel biji buah limus dilakukan di Herbarium Jatinangor, Laboratorium Taksonomi Tumbuhan, Departemen Biologi FMIPA, Universitas Padjajaran, Bandung.

\section{Pengolahan Bahan}

Kernel biji buah limus dikumpulkan dalam keadaan segar, dicuci dan dikeringkan menggunakan oven pada suhu $45^{\circ} \mathrm{C}$. Kemudian dibuat dalam bentuk serbuk halus.

\section{Ekstraksi}

Serbuk kernel biji buah limus diekstraksi dengan metode maserasi menggunakan pelarut etanol 96\% hingga seluruh serbuk kernel biji buah limus terendam. Proses ekstraksi dilakukan selama 3x24 jam dengan sesekali pengadukan. Maserat ditampung dan dipekatkan dengan menggunakan rotary evaporator dan waterbath hingga diperoleh ekstrak kental.

\section{Fraksinasi}

Ekstrak etanol yang telah dipekatkan difraksinasi menggunakan metode partisi. Siapkan lima buah erlenmeyer, masukkan ekstrak kental sebanyak 20 g kedalam masingmasing erlenmeyer. Lakukan partisi pertama dengan pelarut n-heksan. Gojog dalam erlenmeyer selama 6 jam menggunakan alat sheaker orbital, kemudian diamkan selama 18 jam pada suhu kamar sampai larutan n-heksan tidak keruh (tidak ada yang terlarut). Tampung sari 
n-heksan dan uapkan diatas waterbath, sisa partisi dengan n-heksan dipartisi kembali menggunakan pelarut etil asetat, metanol, dan air secara berturut-turut.

\section{Penapisan Fitokimia}

Penapisan fitokimia dilakukan untuk mengetahui kandungan senyawa metabolit sekunder yang terdapat pada tanaman, meliputi identifikasi golongan alkaloid, flavonoid, saponin, steroid dan triterpenoid, tanin dan polifenol, kuinon, mono dan seskuiterpenoid.

\section{Penentuan Kualitatif Aktivitas Antioksidan}

Penentuan kualitatif aktivitas antioksidan dilakukan dengan metode KLT menggunakan fase gerak yang sesuai untuk ekstrak dan masing-masing fraksi dengan penampang bercak DPPH $0,2 \%$ dalam metanol. Hal ini dilakukan untuk mengidentifikasi adanya senyawa antioksidan yang bereaksi positif terhadap pereaksi DPPH, ditunjukkan dengan timbulnya bercak yang berwarna kuning dengan latar belakang ungu.

\section{Penentuan Kuantitatif Aktivitas Antioksidan}

Penentuan kuantitatif aktivitas antioksidan dilakukan dengan metode peredaman radikal bebas DPPH secara spektrofotometri UV-Vis (Molyneux, 2004).

\section{Pembuatan Larutan DPPH}

Sebanyak 78,864 mg serbuk DPPH, larutkan dalam metanol p.a hingga volumenya 100 mL. Pipet $10 \mathrm{~mL}$ dan tambahkan metanol p.a hingga volumenya $100 \mathrm{~mL}$, sehingga diperoleh konsentrasi 0,2 mM yang dihitung terhadap BM DPPH sebesar 394,32 g/mol.

\section{Pembuatan Larutan Uji}

Sebanyak 50 mg ekstrak dan masing-masing fraksi kernel biji limus dimasukkan kedalam labu takar $50 \mathrm{~mL}$ dan tambahkan metanol p.a sampai tanda batas, sehingga diperoleh konsentrasi 1000 ppm (larutan induk). Konsentrasi larutan uji dibuat dengan mempipet larutan induk untuk mendapat seri konsentrasi, seri kadar masing-masing sampel ditentukan berdasarkan hasil uji pendahuluan pengukuran aktivitas antioksidan.

\section{Pembuatan Larutan Induk Vitamin C}

Sebanyak $10 \mathrm{mg}$ vitamin $\mathrm{C}$, larutkan dengan $10 \mathrm{~mL}$ metanol p.a sehingga diperoleh konsentrasi $1 \mathrm{mg} / \mathrm{mL}$ atau $1000 \mu \mathrm{g} / \mathrm{mL}$ sebagai larutan induk. Kemudian dibuat enam seri konsentrasi.

\section{Penentuan Panjang Gelombang}

$2 \mathrm{~mL}$ larutan DPPH 0,2 mM ditambahkan dengan $1 \mathrm{~mL}$ metanol p.a, dikocok sampai homogen. Ukur serapan pada rentang panjang gelombang 400-600 nm.

\section{Penentuan Operating Time}


Masing-masing $1 \mathrm{~mL}$ larutan sampel dan pembanding vitamin $\mathrm{C}$ dikocok dengan $2 \mathrm{~mL}$ larutan DPPH 0,2 mM. Pengamatan absorbansinya dilakukan selama 60 menit pada panjang gelombang $517 \mathrm{~nm}$.

\section{Pengukuran Absorbansi Penangkap Radikal Bebas dengan Metode DPPH}

Masing-masing $1 \mathrm{~mL}$ ekstrak, fraksi kernel biji buah limus, dan larutan pembanding vitamin $\mathrm{C}$ dengan berbagai konsentrasi dikocok kuat dengan $2 \mathrm{~mL}$ larutan DPPH 0,2 mM. Campuran larutan disimpan di tempat gelap, absorbansi sampel diukur pada panjang gelombang serapan maksimal DPPH dengan spektrofotometer UV-Vis. Nilai absorbansi yang diperoleh dihitung persen peredam DPPH oleh sampel dan pembanding.

\section{HASIL DAN PEMBAHASAN}

\section{Hasil Determinasi Tanaman}

Determinasi dilakukan di Herbarium Jatinangor, Laboratorium Taksonomi Tumbuhan, Departemen Biologi FMIPA, Universitas Padjajaran, Bandung. Berdasarkan hasil determinasi diperoleh kepastian bahwa nama spesies tanaman yang digunakan pada penelitian adalah Mangifera foetida Lour.

\section{Hasil Ekstraksi dan Fraksinasi Ekstrak Kernel Biji Buah Limus}

Ekstraksi simplisia kernel biji buah limus dilakukan dengan metode maserasi menggunakan pelarut etanol 96\%, proses ekstraksi menghasilkan rendemen sebanyak 28,78\%. Fraksinasi dilakukan dengan tujuan untuk memisahkan senyawa golongan metabolit sekunder berdasarkan tingkat kepolaran. Persen rendemen ekstrak dan fraksi-fraksi ekstrak yang dihasilkan dapat dilihat pada tabel 1 .

Tabel 1 Hasil Rendemen Ekstrak dan Fraksi Ekstrak Kernel Biji Limus

\begin{tabular}{ccccc}
\hline Sampel & Pelarut & $\begin{array}{c}\text { Berat Sampel } \\
(\text { gram })\end{array}$ & $\begin{array}{c}\text { Berat Ekstrak/Fraksi } \\
\text { Kental } \\
\text { (gram) }\end{array}$ & (\%) Rendemen \\
\hline Ekstrak & Etanol 96\% & 949,57 & 273,07 & 28,7572 \\
Fraksi & N-Hexan & 100 & 1,6380 & 1,638 \\
& Etil Asetat & 100 & 37,4033 & 37,4033 \\
& Metanol & 100 & 30,2307 & 30,2307 \\
& Air & 100 & 1,4545 & 1,4545 \\
\hline
\end{tabular}




\section{Hasil Penapisan Fitokimia}

Penapisan fitokimia bertujuan untuk mengetahui golongan senyawa kimia yang terkandung dalam tumbuhan. Proses penapisan fitokimia dilakukan terhadap simplisia, ekstrak etanol, fraksi n-heksana, fraksi etil asetat, fraksi metanol, dan fraksi air kernel biji buah limus. Hasil dari penapisan fitokimia dapat dilihat pada tabel 2.

Tabel 2. Hasil Penapisan Fitokimia Simplisia, Ekstrak, dan Fraksi Kernel Biji Buah Limus

\begin{tabular}{|c|c|c|c|c|c|c|}
\hline \multirow[b]{2}{*}{$\begin{array}{l}\text { Senyawa Metabolit } \\
\text { Sekunder }\end{array}$} & \multicolumn{6}{|c|}{ Hasil Penapisan Fitokimia } \\
\hline & Simplisia & $\begin{array}{l}\text { Ekstrak } \\
\text { Etanol }\end{array}$ & $\begin{array}{c}\text { Fraksi } \\
\text { N-Heksana }\end{array}$ & $\begin{array}{l}\text { Fraksi } \\
\text { Etil } \\
\text { Asetat }\end{array}$ & $\begin{array}{c}\text { Fraksi } \\
\text { Metanol }\end{array}$ & $\begin{array}{l}\text { Fraksi } \\
\text { Air }\end{array}$ \\
\hline Alkaloid & - & - & - & - & - & - \\
\hline Flavonoid & + & + & - & + & + & - \\
\hline Saponin & - & - & - & - & - & - \\
\hline $\begin{array}{l}\text { Steroid dan } \\
\text { Triterpenoid }\end{array}$ & - & - & - & - & - & - \\
\hline Tanin dan Polifenol & + & + & - & + & + & - \\
\hline $\begin{array}{l}\text { Kuinon } \\
\text { Mono dan } \\
\text { Seskuiterpenoid }\end{array}$ & $\begin{array}{l}+ \\
+\end{array}$ & $\begin{array}{l}+ \\
+\end{array}$ & $\begin{array}{l}+ \\
+\end{array}$ & $\begin{array}{l}+ \\
+\end{array}$ & $\begin{array}{l}+ \\
+\end{array}$ & $\begin{array}{l}+ \\
+\end{array}$ \\
\hline
\end{tabular}

Berdasarkan tabel 2, kernel biji limus positif memiliki senyawa-senyawa yang biasanya dikaitkan dengan aktivitas antioksidan diantaranya adalah flavonoid, tanin, polifenol, kuinon, monoterpen dan seskuiterpenoid.

\section{Hasil Penentuan Kualitatif Aktivitas Antioksidan}

Penentuan kualitatif aktivitas antioksidan menggunakan metode kromatografi lapis tipis (KLT) dengan fase diam plat silika gel $\mathrm{GF}_{254}$ dan fase geraknya toluen:aseton (3,5: 6). Hasil penyemprotan larutan DPPH 2\% dalam metanol terhadap hasil KLT menunjukan bahwa ekstrak dan semua fraksi ekstrak memiliki aktivitas sebagai antioksidan dengan adanya perubahan warna spot pada kromatogram menjadi kuning dengan latar warna ungu yang berasal dari warna DPPH yang disemprotkan.

\section{Hasil Penentuan Kuantitatif Aktivitas Antioksidan}

Penentuan kuantitatif aktivitas antioksidan dilakukan dengan metode DPPH menggunakan Spektrofotometer UV-Vis. Pengukuran aktivitas antioksidan ekstrak biji limus dilakukan menggunakan metode DPPH. Uji DPPH didasarkan pada kemampuan antioksidan untuk menyumbangkan radikal hidrogen yang radikal bebas stabil dengan warna ungu tua. Ketika elektron ganjil dipasangkan dengan adanya pemulung radikal bebas dari zat antioksidan, radikal DPPH diturunkan menjadi hidrazin yang sesuai, bentuk DPPH-H dan solusinya dihilangkan dari ungu awal menjadi warna kuning muda (Khuma, 2017). 
Pengujian aktivitas antioksidan pada ekstrak dan fraksi kernel biji buah limus dilakukan dengan mereaksikan sampel dengan larutan DPPH (1:2). Waktu inkubasi yang dibutuhkan oleh sampel dan fraksi sama, yaitu 30 menit. Nilai ES$_{50}$ menunjukkan konsentrasi sampel yang mampu menghambat aktivitas suatu radikal bebas sebesar 50\% yang diperoleh dari perhitungan regresi linier antara konsentrasi sampel dengan persen inhibisi. Semakin kecil nilai $\mathrm{ES}_{50}$, maka semakin kuat aktivitas antioksidannya (Budilaksono et al., 2014). Nilai ES50 dan intensitas aktivitas antioksidan pembanding, ekstrak, dan fraksi kernel biji buah limus dapat dilihat pada tabel 3.

Tabel 3 Nilai IC50 dan Intensitas Aktivitas

\begin{tabular}{ccc}
\hline Sampel & $\mathrm{ES}_{50}(\mu \mathrm{g} / \mathrm{mL})$ & Intensitas Antioksidan \\
\hline Vitamin C & $2.436 \pm 0.055$ & Sangat Kuat \\
Ekstrak Etanol & $8.922 \pm 0.037$ & Sangat Kuat \\
Fraksi N-Hexan & $10,004 \pm 0.004$ & Sangat Kuat \\
Fraksi Etil Asetat & $1,164 \pm 0.005$ & Sangat Kuat \\
Fraksi Metanol & $9,289 \pm 0.043$ & Sangat Kuat \\
Fraksi Air & $27.900 \pm 0.175$ & Sangat Kuat \\
\hline
\end{tabular}

Tabel 3 menunjukan bahwa fraksi etil asetat memiliki aktivitas antioksidan yang lebih kuat dari senyawa pembanding, ekstrak dan fraksi lainnya dengan nilai $\mathrm{ES}_{50} 1,164 \pm 0.005$ $\mu \mathrm{g} / \mathrm{mL}$. Hail ini menunjukan bahwa hanya dengan konsentrasi tersebut fraksi etil asetat sudah mampu meredam $50 \%$ DPPH sebagai radikal bebasnya. Berdasarkan skrining fitokimia pada tabel 2, fraksi etil asetat mengandung golongan senywa metabolit sekunder diantaranya flavonoid, polifenol, tanin, kuinon, monoterpen dan seskuiterpen. Golongan senyawa kimia tersebut banyak dilaporkan memiliki khasiat antioksidan. Kandungan fenolik dan flavonoid memberikan aktivitas antioksidan (Mayers et al, 2003). Jumlah total dan konfigurasi kelompok hidroksil yang ada pada senyawa dapat meningkatkan efek antioksidan dan antidiabetes dari flavonoid (Sarian, dkk 2017). Selain itu monoterpenoid dan seskuiterpenoid merupakan komponen penyusun minyak atsiri. Tanin merupakan senyawa polifenol yang memilki aktivitas antioksidan. Minyak atsiri juga banyak dilaporkan memberikan aktivitas antioksidan yang baik.

\section{PENUTUP}

Ekstrak etanol, fraksi n-heksana, fraksi etil asetat, fraksi metanol, dan fraksi air kernel biji buah limus yang diuji menggunakan metode DPPH memiliki aktivitas antioksidan yang sangat kuat. Fraksi etil asetat memiliki aktivitas antioksidan lebih kuat dari vitamin C, sehingga 
sangat berpotensi sebagai sumber antioksidan alami. Elusidasi struktur dengan bioassay guided isolation dapat dilakukan untuk memastikan senyawa apa yang sangat berpotensi sebagai antioksidan pada biji limus ini. Adanya pegembangan dalam suantu pruduk sedian farmasi akan menambah kemanfaatan dari biji limus ini terutama sebagai antioksidan. Pengujian invivo khasiat antioksidan biji limus disarankan untuk dilakukan sehingga kajian efektivitas farmakologinya semakin kuat.

\section{DAFTAR PUSTAKA}

Anonim, 2008, Farmakope Herbal Indonesia, Edisi I, Departemen Kesehatan Republik Indonesia, Jakarta.

Amrun, M., Umiyah, \& Umayah, E., 2007, Uji Aktivitas Antioksidan Ekstrak Air Dan Ekstrak Metanol Beberapa Varian Buah Kenitu (Chrysophyllum cainito L.) dari daerah Jember. Berk. Penel. Hayati 2007; 13:45-50

Barreira JCM., Ferreira ICFR., Oliveira MBPP., Pereira JA., 2008, ‘Antioxidant activities of the extracts from chestnut flower, leaf, skins and fruit'. Food Chem, 107:11061113.

Meyers KJ, Watkins CB, Pritts MP, Liu RH., 2003, 'Antioxidant and antiproliferative activities of strawberries'. J Agric Food Chem, 51: 6887-6892.

Mirfat AHS, Salma I, Razali M., 2016, Natural antioxidant properties of selected wild Mangifera species in Malaysia. J Trop Agric Food Sci.; 44(1):63- 72.

Muchtadi, Deddy. (2013). Antioksidan dan Kiat Sehat di Usia Produktif. Alfabeta. Bandung.

Lie Jin, 2012, Phenolic Compound and Antioxidan Activity of Bulb Extract of Six Lilium Species Native to China, Molecules, hlm. 9362.

Khuma Sharma Dhita., 2017, 'Phytochemical screening and antioxidant activities ofMangifera indica leaves grown in temperate region of the Nepal'. Journal Pharmacognosy and Phytochemstry, 6(3): 205-209

Sarian, Murni Nazira., Ahmed, Qamar Uddin., Mat So’ad, Siti Zaiton., Alhassan, Muhammad Alhassan., Murugesu, Suganya., Perumal, Vikneswari., Sharifah Nurul Akilah Syed Mohamad, Khatib, Alfi., Latip, Jalifah., 2017, 'Antioxidant and Antidiabetic Effects of Flavonoids: A Structure-Activity Relationship Based Study'. BioMed Research International, Volume 2017, Article ID 8386065: 14 pages 